RUNNING HEAD: Voluntary Choice and Choice-outcome Causation

\title{
Belief in Control: Voluntary Choice Enhances Subsequent Task Performance under Undefeated Choice-Outcome Causation
}

Xiaoxiao Luo $^{\text {a, b, 1, * }}$, Lihui Wang ${ }^{\text {c, d, } 1}$, Xiaolin Zhou ${ }^{\text {a, b, e, f, * }}$

${ }^{\text {a }}$ Shanghai Key Laboratory of Mental Health and Psychological Crisis Intervention, School of Psychology and Cognitive Science, East China Normal University, Shanghai, China

${ }^{\mathrm{b}}$ School of Psychological and Cognitive Sciences, Peking University, Beijing, China

${ }^{c}$ Shanghai Key Laboratory of Psychotic Disorders, Shanghai Mental Health Center, Shanghai Jiao Tong University School of Medicine, Shanghai, China

${ }^{\mathrm{d}}$ Institute of Psychology and Behavioral Science, Shanghai Jiao Tong University, Shanghai, China

${ }^{\mathrm{e}}$ Beijing Key Laboratory of Behavior and Mental Health, Peking University, Beijing, China ${ }^{\mathrm{f}}$ PKU-IDG/McGovern Institute for Brain Research, Peking University, Beijing, China

${ }^{1}$ These authors contributed equally to this work.

* Corresponding author at:

School of Psychology and Cognitive Science, East China Normal University, 3663 N.

Zhongshan Rd., Shanghai 200062, China. Email: luoxiao2@126.com (X. Luo).

School of Psychological and Cognitive Sciences, Peking University, No.5 Yiheyuan Road, Haidian District, Beijing 100871, China. Email: xz104@pku.edu.cn (X. Zhou). 


\begin{abstract}
Humans are believed to have volition through which they act upon and change the external environment. As an exercise of volition, making a voluntary choice facilitates the subsequent behavioral performance relative to a forced choice. However, it is unclear how this facilitation is constrained by the perceived relationship between a choice and its outcome. In a series of experiments, participants were free or forced to choose one of two presented pictures. The outcome of the choice was then revealed, which could be always the chosen picture or always the unchosen picture (i.e., a confirmed choice-outcome causation), a blank screen with no picture at all (i.e., an unrevealed choice-outcome relation), the chosen or unchosen picture with equal probability (i.e., a defeated choice-outcome causation), or a third picture different from the two preceding options (again, a defeated choice-outcome causation). Participants then complete a visual search task with the task-irrelevant picture (or the blank screen) serving as a background. Results showed that the search performance was improved after a voluntary choice under both the confirmed causation and the unrevealed relation, but not under the defeated causation. Over individuals, the improved performance due to voluntary choice under confirmed causation positively correlated with the improved performance under the unrevealed relation, and with the reported belief in controlling the outcome of the choice. Our findings suggest that the exercise of volition motivates subsequent behavior, and this motivation is restricted to an "undefeated" choice-outcome causation which affords a belief in controlling the outcome by exerting volition.
\end{abstract}

\title{
Keywords
}

voluntary choice; volition; choice-outcome relation; control belief; visual search 


\section{Introduction}

Every day we make choices, ranging from choosing which shirt to wear to choosing which public policy to vote for. It is believed that humans are born to make choices (Leotti, Iyengar, \& Ochsner, 2010), and that even not to choose is still a choice. A voluntary choice can express human volition. By making voluntary choices (i.e., freely choosing an option among alternatives) versus forced choices (i.e., being forced to choose a predefined option), we exercise control over the environment and gain the sense of agency and self-efficacy (Bandura \& Wood, 1989; Haggard, 2017, 2019).

\subsection{Making voluntary choices facilitates subsequent task performance}

In a choice-task paradigm where participants are asked to make a choice before completing a task, it has been shown that relative to a forced choice, making a voluntary choice improves the subsequent performance in a broad range of tasks (e.g., Lewthwaite, Chiviacowsky, Drews, \& Wulf, 2015; Murayama, Matsumoto, Izuma, Sugiura, Ryan, \& Deci et al., 2015; Murty, DuBrow, \& Davachi, 2015; Patall, Cooper, \& Robinson, 2008; Sanli, Patterson, Bray, \& Lee, 2013). For example, students performed better on classroom tests when they could freely choose one of different homework before the test compared with when they had no choice (Patall, Cooper, \& Wynn, 2010); In motor learning tasks, learners who could freely choose a practice context (e.g., the amount of practice repetitions, the repetition order during multi-task learning, etc.) learned faster than learners whose practice context was predefined (Sanli et al., 2013)

Moreover, the improved performance after a voluntary choice was observed even when making a choice "irrelevant" to the subsequent task (Lewthwaite et al., 2015; Murayama et al., 2015; Murty et al., 2015). For example, in a golf putting task, participants who could freely choose the color of golf balls performed better than those who were forced to choose the predefined color (Lewthwaite et al., 2015); in a time estimation task, participants 
performed better when they could freely choose the appearance of the stopwatch used in the task compared to when they were forced to choose the predefined appearance (Murayama et al., 2015).

\subsection{The explanation of the facilitatory effect of making voluntary choices}

Despite the evidence for a facilitatory effect, it is yet unclear why a voluntary choice can facilitate the subsequent task performance. A frequently discussed account is that making a voluntary choice is valuable and rewarding, which satisfies the need for control or autonomy, and hence, enhances motivation in the subsequent task (Deci \& Ryan, 1985; Leotti et al., 2010; Leotti \& Delgado, 2011, 2014; Murayama, Izuma, Aoki, \& Matsumoto, 2016; Patall, 2019; Reber, Canning, \& Harackiewicz, 2018). Considering the fact that even making a taskirrelevant voluntary choice could facilitate the subsequent task performance (Lewthwaite et al., 2015; Murayama et al., 2015; Murty et al., 2015), we may come to the notion that the opportunity or the mere action of choosing voluntarily is sufficient to motivate subsequent behavior (Deci \& Ryan, 1985; Reber et al., 2018).

This notion emphasizes the act of making a voluntary choice, but little attention is paid on the role of the outcome of the choice, which is at odds with real-world situations where most actions are undertaken to achieve specific outcomes. One of the core features of human volition is teleology - a voluntary action is made for the reason of achieving or advancing a goal state through that action (Haggard, 2019). It has been shown that the selection of a voluntary action depends critically on the associations between the action and the outcome (Chambon, Théro, Vidal, Vandendriessche, Haggard, \& Palminteri, 2020; Elsner \& Hommel, 2004; Soon, Brass, Heinze, \& Haynes, 2008). Humans are inclined to build up a causal relation between a voluntary action and the appearance of a certain outcome following that action (Desantis, Roussel, \& Waszak, 2011; Dogge, Schaap, Custers, Wegner, \& Aarts, 2012; Moore \& Haggard, 2008). A strong belief in this causal relation results in a strong 
engagement of behavioral efforts (Bandura \& Wood, 1989), and undermining this belief attenuates the motivation to act (Huys \& Dayan, 2009; Rigoni, Kühn, Sartori, \& Brass, 2011). Similarly, individuals' motivation to perform can be enhanced when actions have even trivial and constant perceptual effects (Eitam, Kennedy, \& Higgins, 2013; Karsh, Eitam, Mark, \& Higgins, 2016; Karsh \& Eitam, 2015). It is possible that whether a voluntary choice motivates subsequent behaviors depends crucially on to what extent the outcome of choice is believed to be controlled by the choice, rather than on the mere action of choosing.

In previous studies which showed that voluntary choices facilitated subsequent behaviors, the outcome of the choice always turned out to be the chosen option. For instance, choosing a homework option in the classroom was followed by doing the chosen homework after school (Patall et al., 2010); choosing the color of a golf ball was followed by the inclusion of the golf ball with the chosen color in the subsequent putting task (Lewthwaite et al., 2015). Given the constant linkage between the choice and its outcome, a causal relation could be built up in the way that the choice causes the outcome to appear despite the fact that the relation between the choice and its outcome can be manipulated. By manipulating this choice-outcome relation, here we investigate how the facilitatory effect of voluntary choice could be constrained; and the extent to which these constraints can help facilitate the effect of voluntary choice, revealing the mechanism underlying the facilitatory effect.

\subsection{The present study}

In this study, we investigate how performance in a simple cognitive task, namely visual search (Theeuwes, 1991; Wolfe, 1994), is affected by a preceding voluntary (vs. forced) action of choosing between two alternative pictures which could serve as a task-irrelevant background picture in the search task. Crucially, the relation between the act of making a choice (i.e., choosing a picture) and its outcome (i.e., the appearing of a picture after the choice) was manipulated by changing the presentation of the background picture (Figure 1). 


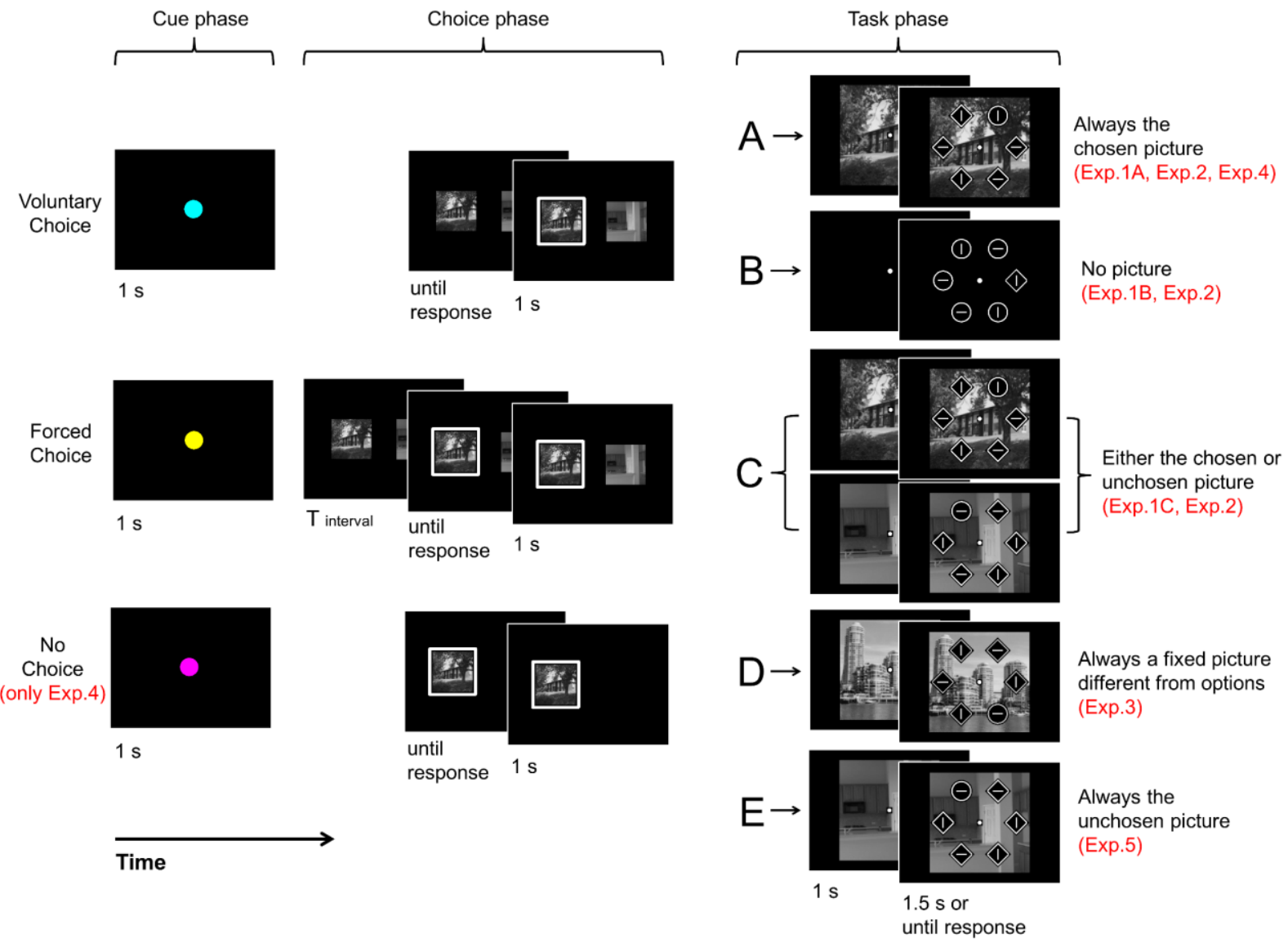

Figure 1 The sequence of events for all Experiments. Each trial consisted of three successive phases: the cue phase, the choice phase, and the task phase. In the cue phase, a colored dot was presented to signal the choice type in the current trial. In the choice phase of the voluntary and forced choice conditions, two pictures were presented and participants were free (voluntary choice) or forced (forced choice) to choose one by button press. Note that the screen lasting for $\mathrm{T}_{\text {interval }}$ in the forced choice condition was to balance the exposure time between conditions (for details see Pilot Experiment in Supplementary Materials).

Specifically, in Experiment 4, an additional "no choice" condition was included, in which only one picture was presented and participants were asked to indicate the location (left vs. right) of the picture. Then in the task phase, participants were asked to complete a visual search task in which the search target was a unique shape among distractors. Crucially, there was a task-irrelevant background for the visual search task, which could be: (A) always the chosen picture (i.e., a confirmed choice-outcome causation) in Experiments 1A and 4, (B) always a blank screen where no picture was presented at all (i.e., an unrevealed choiceoutcome relation) in Experiment 1B, (C) either the chosen or the unchosen picture with equal probability (i.e., a defeated choice-outcome causation) in Experiment 1C, (D) always a fixed picture that had never been presented as an option in the choice phase (i.e., again a defeated choice-outcome causation, but the outcome of choice was predictable) in Experiment 3, and (E) always the unchosen picture (i.e., a confirmed choice-outcome causation, although the previous choice was unfulfilled) in Experiment 5. Experiment 2 included $(\mathbf{A}),(\mathbf{B})$, and $(\mathbf{C})$ in a within-subject design. There were blank screens with fixation between phases, which were not shown in this figure. 
In Experiment 1 (Figure 1A, B, and C), the causal relation between the choice and its outcome was confirmed by the presentation of the chosen picture as the background (i.e., the background could be controlled by the preceding choice), or defeated by the presentation of either the chosen or unchosen picture with equal probability (i.e., the background could not be controlled by the preceding choice). In another setting, namely unrevealed relation, no picture was presented after choices, and hence the causal relation was neither confirmed nor defeated. It appears that this "unrevealed relation" is similar to the "defeated causal relation"; since "no outcome after choices" is seemingly equivalent to "the outcome cannot be controlled by the choice". However, there is evidence that making a voluntary action and anticipating a possible outcome is sufficient for the sense of agency, whereas the actual presentation of the outcome is not necessary (Moore, Lagnado, Deal, \& Haggard, 2009; Moore \& Haggard, 2008). Thus, it is possible that individuals would (implicitly) anticipate the outcome of a voluntary choice before an outcome was actually revealed, and still hold the (implicit) belief that the outcome could be controlled by the choice.

Therefore, both the confirmed causation and the unrevealed relation may afford a belief in controlling the outcome by making a voluntary choice, whereas the defeated causation may weaken or eliminate this belief. Thus, we predicted that the visual search performance would be enhanced after making a voluntary (vs. forced) choice under the confirmed causation and the unrevealed relation, but not under the defeated causation.

While the different choice-outcome relations in Experiment 1 were conducted on different groups of individuals, Experiment 2 tested the reliability of the results with a withinsubject design.

In Experiment 3 (Figure 1D), we tested an alternative account, that is, the facilitatory effect of voluntary choice was due to the high predictability of the outcome of the choice, rather than the choice-outcome causation. To test this account, we fixed the outcome of the choice by always presenting one constant picture as the background such that the outcome 
(i.e., the background picture) was fully predictable, but unrelated to the choice (i.e., could not be controlled by the preceding choice, forming a defeated choice-outcome causation). We predicted that the facilitatory effect of voluntary choice would still be observed if this effect could be explained by the predictability account.

In Experiment 4, we added a baseline (no choice) condition in which participants completed a picture-localization task (see the bottom-left panel of Figure 1) before the visual search. This localization task did not involve any explicit choice making but just a button press. The baseline condition would allow us to adjudicate whether a voluntary choice improves (i.e., motivates) or a forced choice impairs (i.e., demotivates) the subsequent task performance.

In Experiment 5, the unchosen picture was presented as the background (Figure 1E), leading to an undesired situation where the actual choice was unfulfilled. However, participants could mitigate this situation and maintain the choice-outcome causation by choosing the unwanted option. This arrangement would discriminate whether the facilitatory effect of voluntary choice was more due to the fulfilled voluntary choice or the controllable outcome by making a voluntary choice. We predicted that the facilitated performance would still be observed because the choice-outcome causation still held. To provide collaborative evidence, we also collected post-experiment data concerning participants' subjective feelings (e.g., control belief) under the voluntary and forced choice conditions to evaluate if the observed facilitatory effect correlated with these characteristics. 


\section{Methods}

\subsection{Participants}

Seventy-two university students participated in Experiment 1 (42 females, 18-28 years old, $M=21.1, S D=2.4)$. They were randomly divided into three groups of the same size $(n=$ 24), with one group assigned to Experiment $1 \mathrm{~A}$ (14 females, 18-26 years old, $M=21.1, S D=$ 2.4), another group to Experiment 1B (13 females, 18-28 years old, $M=21.5, S D=2.7$ ), and the third group to Experiment $1 \mathrm{C}$ ( 15 females, $18-28$ years old, $M=20.6, S D=2.6$ ). The sample size $(n=24)$ in each experiment was determined by a prior power analysis for paired $t$ test (two-tailed, $\alpha=0.05$, power $=80 \%$, and $d=0.61$ ) using G*Power 3.1 (Faul, Erdfelder, Lang, \& Buchner, 2007). The effect size $(d=0.61)$ was obtained from a pilot experiment (see Pilot Experiment in Supplementary Materials). Another group of 27 university students participated in Experiment 2 (19 females, 18-25 years old, $M=20.9, S D=1.9)$. We recruited more participants for this experiment out of fear that some participants could withdraw from the study due to longer testing time. A new group of 24 university students took part in Experiment 3, one participant was excluded from data analysis due to low accuracy $(<3 S D$ below the group mean), thus, 23 participants ( 11 females, 18-26 years old, $M=21.9, S D=$ 2.4) were included. A new group of 24 university students took part in Experiment 4 (18 females, $18-28$ years old, $M=21.5, S D=3.0$ ). At last, a new group of 36 university students took part in Experiment 5 (20 females, 18-26 years old, $M=20.7, S D=2.3$ ). We recruited more participants for Experiment 5 because we planned to conduct correlation analyses and more participants would be desirable.

All participants were right-handed and had normal or corrected-to-normal vision and normal color vision. None of them reported a history of neurological or psychiatric disorders. This study was performed in accordance with the Declaration of Helsinki and was approved by the Committee on Human Research Protection, East China Normal University, and by the Committee for Protecting Human and Animal Subjects, School of Psychological and 
Cognitive Sciences, Peking University. Informed consent was obtained from each of the participants prior to the experiment. All participants received monetary compensation for taking part in the experiment.

\subsection{Stimuli and procedure}

Participants were seated $70 \mathrm{~cm}$ away from a monitor $(44 \times 33 \mathrm{~cm}$, refresh rate: $100 \mathrm{~Hz}$, resolution: $1024 \times 768$ pixels) connected to a $\mathrm{PC}$ with their head positioned on a chin-rest in a dimly-lighted and sound-attenuated room. Experiments were run with Psychophysics Toolbox (Brainard, 1997, http://www.psychtoolbox.org/) on Matlab. The trial structure is shown in Figure 1. All experiments consisted of two conditions (i.e., the voluntary and forced choice conditions, see the top-left and middle-left panels of Figure 1) except for Experiment 4, where a third condition was added (i.e., the no choice condition, see the bottom-left panel of Figure 1), which will be described later.

\subsubsection{Experiment 1}

Each trial consisted of three successive phases: the cue phase, the choice phase, and the task phase. In the cue phase, a small white dot $\left(0.7^{\circ} \times 0.7^{\circ}\right)$ was presented on the black screen as the central fixation for $0.8-1.2 \mathrm{~s}$. Then a central dot $\left(1.6^{\circ} \times 1.6^{\circ}\right)$ either in cyan or yellow was presented for $1 \mathrm{~s}$ to indicate whether the upcoming choice was voluntary or forced. The association between different colors (cyan or yellow) and different types of choice (voluntary or forced) was counterbalanced across participants.

In the choice phase, after the central fixation presented for $0.5-0.8 \mathrm{~s}$, a pair of two pictures (each $5.3^{\circ} \times 5.3^{\circ}$ ) was presented $4.9^{\circ}$ left and right to the center of the screen, waiting for a button press of choosing. In the voluntary choice condition, participants could freely choose a picture by pressing "D" (left picture) or "F" (right picture) using the middle or index finger on the left hand. The chosen picture was then marked with a grey frame after the button 
press. In the forced choice condition, however, one of the two pictures was randomly selected and marked with a grey frame, and participants had to choose the marked picture by button press. Note that the two pictures would be firstly presented for a pre-defined varying time interval ( $\left.T_{\text {interval }}\right)$ until one of the two pictures was marked by the frame. This was to balance the exposure times to the picture options between the voluntary and forced choice conditions (for details see Pilot Experiment in Supplementary Materials). After the button press, the two pictures together with the grey frame were presented for another $1 \mathrm{~s}$ in both conditions.

The cue phase and the choice phase were kept the same for Experiment 1A, 1B and 1C. These three experiments differed only in the task phase. For Experiment 1A, after the central fixation lasted for $0.5-0.8 \mathrm{~s}$, the chosen picture $\left(11.4^{\circ} \times 11.4^{\circ}\right)$ was presented at the center of the screen for $1 \mathrm{~s}$; For Experiment 1B, no picture was presented, and the central fixation was presented for $1 \mathrm{~s}$; For Experiment 1C, either the chosen or unchosen picture was presented with equal probability (i.e., 50\%) for $1 \mathrm{~s}$ after the $0.5-0.8 \mathrm{~s}$ central fixation (these settings were explicitly told to participants). Then a visual search array consisting of six grey items (one diamond among five circles or one circle among five diamonds, each $2.5^{\circ} \times 2.5^{\circ}$ ) was presented equidistantly along an imaginary circle $\left(4.9^{\circ}\right.$ radius $)$. A white line segment (length $1.6^{\circ}$, either horizontal or vertical) was presented inside of each item. This search array was presented on the top of the background picture (or the blank screen) and remained on the screen for $1.5 \mathrm{~s}$ until a button press was given. Participants were asked to find the unique shape and indicate the orientation of the line segment inside that shape by pressing "J" or "K" using the index or middle finger on the right hand. The mapping between the keys ("J" or "K") and the two orientations (horizontal or vertical) was counterbalanced across participants. Participants were informed to respond within the $1.5 \mathrm{~s}$ as quickly and accurately as possible. A feedback, "Too slow!", was presented for $0.5 \mathrm{~s}$ if no response was given within the $1.5 \mathrm{~s}$. In each experiment in Experiment 1, there were 120 trials for each of the two choice conditions (voluntary vs. forced), resulting in 240 trials in total, which were intermixed and 
divided into 5 blocks (48 trials each). The two conditions were distributed with equal probability in each block. Prior to the formal experiment, participants were provided with 48 practice trials with only the task phase where no background picture was presented. Participants were required to repeat the practice trials if the accuracy was below $75 \%$. Then participants were provided with 10 example trials with all three phases.

A total of 250 pictures of outdoor houses or indoor furnishings in black and white were used as the choice options, with 240 pictures for the formal experiment and 10 pictures for the example trials. For each participant, the 240 pictures were randomly divided into 120 pairs without repetition. The same 120 pairs were presented as options in the choice phase of both conditions, with each pair appearing only once in each condition.

\subsubsection{Experiment 2}

The stimuli and procedure of Experiment 2 were the same as Experiment 1, except that Experiment 2 had a within-subject design. All participants in Experiment 2 completed the three experiments in Experiment 1 on three separate days. The order of the three experiments was counterbalanced across participants.

\subsubsection{Experiment 3}

The stimuli and procedure of Experiment 3 were the same as Experiment 1A, except that the background in the task phase during the whole experiment was always the same picture that had never been presented in the choice phase.

\subsubsection{Experiment 4}

The stimuli and procedure of Experiment 4 were the same as Experiment 1A with the following exceptions. We added a third condition (i.e., no choice condition) to the voluntary and the forced choice conditions. Specifically, in this condition, a dot in a color different from 
the other two conditions (e.g., pink) was presented to indicate the no choice condition in the upcoming trial (the mapping between the three colors and the three choice conditions were counterbalanced across participants). In the choice phase of the no choice condition, only one picture with a marked frame was presented left or right to the center of the screen, and participants were asked to indicate the location of the picture by pressing " $D$ " (if the picture was on the left) or "F" (if the picture was on the right). The task phase was the same as the voluntary and forced choice conditions. There were 96 trials for each of the three conditions (288 trials in total), which were intermixed and divided into 8 blocks ( 36 trials each). There were 192 pictures (i.e., 96 pairs) were used in Experiment 4. All the pictures showed in the no choice condition was the same as the chosen pictures in the forced choice condition.

\subsubsection{Experiment 5}

The stimuli and procedure of Experiment 5 were the same as Experiment 1A, except that the background picture in the task phase was the unchosen picture. Moreover, after finishing the computer task, participants were asked to complete a series of subjective rating questions (7-points Likert), including: (1) Control belief: "To what extent do you feel that the background of the search task could be controlled by yourself when you/the computer chose a picture?". (2) Happiness: "How happy do you feel in the search task when you/the computer chose a picture?". (3) Preference: "How much do you like the search task when you/the computer chose a picture?”. (4) Difficulty: “How difficult do you feel the search task is when you/the computer chose a picture?".

\subsection{Statistical Analyses}

For each participant in each experiment, omissions (i.e., no response was given within $1.5 \mathrm{~s}$ after the onset of the search array, which were regarded as "incorrect"), trials with incorrect response in the visual search task, and trials with RTs (including RTs of visual 
search in the task phase and RTs of choice in the choice phase) below $100 \mathrm{~ms}$ or beyond 3SD above or below the mean RT in each condition were excluded from RT analysis. The mean RT was then calculated based on the remaining trials for the visual search task in each condition. Accuracy was calculated as the proportion of correct trials in all trials. Statistical analysis was performed on both RTs and accuracies of the visual search task. In case where a null hypothesis was accepted under a non-significant effect of the $t$ test, we calculated the Bayesian Factor, $\mathrm{BF}_{01}$ (Wagenmakers, Marsman, Jamil, Ly, Verhagen, \& Love et al., 2018), using JASP (Wagenmakers, Love, Marsman, Jamil, Ly, \& Verhagen et al., 2018) to quantify the extent to which the null hypothesis was supported. 


\section{Results}

Table 1 summarizes the main RT results of all the experiments. Results concerning response accuracy in visual search, which showed no effect of experimental manipulation, are shown in Table S1 in Supplementary Materials.

Table 1 A summary of experimental conditions and reaction time (RT) results in visual search, with standard deviations in parentheses

\begin{tabular}{|c|c|c|c|c|c|c|}
\hline \multirow[b]{2}{*}{ Experiment } & \multirow{2}{*}{$\begin{array}{l}\text { Background of } \\
\text { visual search }\end{array}$} & \multirow{2}{*}{$\begin{array}{l}\text { Choice- } \\
\text { outcome } \\
\text { relation }\end{array}$} & \multicolumn{4}{|c|}{ RTs in visual search (ms) } \\
\hline & & & $\begin{array}{c}\text { Voluntary choice } \\
\text { condition }\end{array}$ & $\begin{array}{c}\text { Forced choice } \\
\text { condition }\end{array}$ & $\begin{array}{l}\text { No choice } \\
\text { condition }\end{array}$ & $\begin{array}{l}\text { Facilitatory effect } \\
\text { of voluntary choice }\end{array}$ \\
\hline Experiment 1A & Chosen picture & Confirmed & $880(81)$ & $903(83)$ & / & $23(20) * * *$ \\
\hline Experiment 1B & None & Unrevealed & $869(104)$ & $893(100)$ & / & $24(20)^{* * *}$ \\
\hline Experiment 1C & $\begin{array}{l}\text { Either chosen or } \\
\text { unchosen picture }\end{array}$ & Defeated & $907(88)$ & $906(91)$ & / & $-1(24)$ \\
\hline \multirow[t]{3}{*}{ Experiment 2} & 1. Chosen picture & Confirmed & $809(89)$ & $815(83)$ & / & $6(15)^{*}$ \\
\hline & 2. None & Unrevealed & $805(105)$ & $819(105)$ & / & $14(21)^{* *}$ \\
\hline & $\begin{array}{l}\text { 3. Either chosen or } \\
\text { unchosen picture }\end{array}$ & Defeated & $831(90)$ & $832(90)$ & / & $1(24)$ \\
\hline Experiment 3 & $\begin{array}{l}\text { A fixed picture } \\
\text { different from } \\
\text { options }\end{array}$ & Defeated & $887(105)$ & $893(105)$ & / & $6(25)$ \\
\hline Experiment 4 & Chosen picture & Confirmed & $862(98)$ & $876(96)$ & $879(99)$ & $14(25)^{*}$ \\
\hline Experiment 5 & Unchosen picture & Confirmed & $868(113)$ & $879(114)$ & / & $11(25)^{*}$ \\
\hline
\end{tabular}

Note: The facilitatory effect of voluntary choice was calculated by subtracting the RT in the voluntary choice condition from the RT in the forced choice condition. $* p<.05, * * p<.01, * * * p<.001$.

\subsection{Experiment 1}

In Experiment 1A where the background of the visual search task was always the chosen picture (i.e., the outcome could be controlled by the choice, Figure 1A), participants responded faster in the search task after a voluntary choice than after a forced choice (Table $1), t(23)=5.69, p<.001, d=1.16$, demonstrating improved performance after a voluntary choice when the choice-outcome causation is confirmed. Moreover, we provided the same pairs of pictures in the two conditions and sorted trials according to whether the chosen pictures were the same or different in the conditions (see Methods for details and Table S2 for the trial proportions). The 2 (Choice Type: voluntary vs. forced) $\times 2$ (Chosen Picture: same 
vs. different) repeated-measures ANOVA on RTs of the search task showed that neither the main effect of Chosen Picture, $F(1,23)=1.50, p=.233, \eta_{p}^{2}=.06$, nor the interaction, $F(1$, $23)=0.33, p=.574, \eta_{p}{ }^{2}=.01$, reached significance, that is, the improved performance after a voluntary choice was observed regardless of whether the chosen pictures in the voluntary choice condition was the same as or different from the chosen pictures in the forced choice condition (Figure 2A), suggesting that the improved performance was not due to the difference in background pictures between the two conditions.
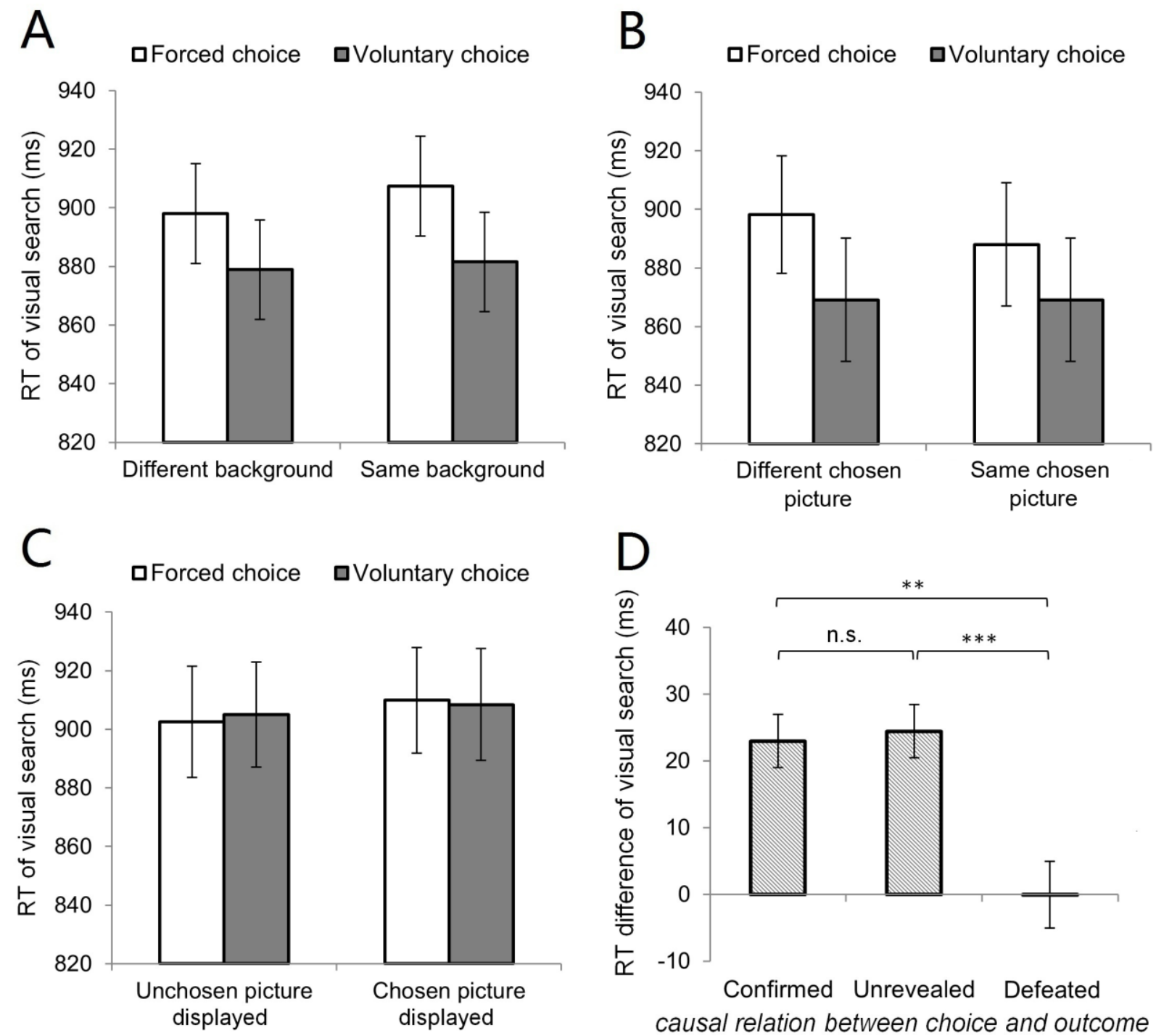

Figure 2 Control analyses of Experiment 1. (A) The reaction time (RT) of visual search as a function of Choice Type and Chosen Picture in Experiment 1A. The improved search performance in the voluntary choice condition was observed regardless of whether the chosen pictures in the voluntary choice condition was the same as or different from the chosen 
pictures in the forced choice condition. (B) The RT of visual search as a function of Choice Type and Chosen Picture in Experiment 1B. The same pattern as Experiment 1A was observed in Experiment 1B. (C) The RT of visual search as a function of Choice Type and Background Picture in Experiment 1C. The search performance did not differ between the voluntary and forced choice conditions regardless of whether the background of visual search was the chosen or unchosen picture. (D) The RT differences between the voluntary choice condition and the forced choice condition in Experiment 1A (confirmed causal relation), 1B (unrevealed relation), and $1 \mathrm{C}$ (defeated causal relation). ${ }^{* *} p<.01,{ }^{* * *} p<.001$, error bars denote SEM.

In Experiment 1B where no picture was presented as the search background (i.e., no outcome after a choice, Figure 1B), participants were still faster in the search task after a voluntary choice than after a forced choice (Table 1), $t(23)=5.94, p<.001, d=1.21$, suggesting improved performance after a voluntary choice even when the choice-outcome relation was unrevealed. As in Experiment 1A, the improved search performance after a voluntary choice could not be due to the difference in chosen pictures between conditions (Figure 2B, neither the main effect of Chosen Picture, $F(1,23)=1.68, p=.208, \eta_{p}{ }^{2}=.07$, nor the interaction, $F(1,23)=1.04, p=.318, \eta_{p}{ }^{2}=.04$, reached significance).

In Experiment 1C where the background picture could be either the chosen or unchosen picture (i.e., the outcome could not be controlled by the choice, Figure 1C), the RTs of visual search did not differ between the voluntary and forced choice conditions (Table 1), $t(23)=$ $0.09, p=.930$. This null effect was confirmed by the $\mathrm{BF}_{01}=4.64$, suggesting that the null hypothesis was 4.64 times more likely to be true than the alternative hypothesis. Moreover, to examine if the improved search performance occurred only when the chosen picture was presented as the background, a 2 (Choice Type: voluntary vs. forced) $\times 2$ (Background Picture: chosen vs. unchosen) repeated-measures ANOVA was conducted on the RTs, which showed that neither the main effect of the Background Picture, $F(1,23)=1.67, p=.209, \eta_{p}^{2}$ $=.07$, nor the interaction, $F(1,23)=0.12, p=.736, \eta_{p}{ }^{2}=.01$, reached significance, that is, the lack of improved performance was robust, regardless of whether the displayed background was the chosen or unchosen picture (Figure 2C). These results suggested that 
when the outcome turned out to be unrelated to the choice (i.e., the choice-outcome causation is defeated), a voluntary choice has no impact on the following performance compared with a forced choice.

It is clear from the above results that whether a voluntary choice facilitates the subsequent performance depends crucially on the choice-outcome relation. To further verify this pattern, we compared the RT difference between the voluntary and forced choice conditions across the three experiments (Figure 2D). The main effect of experiments was significant, $F(2,69)=10.12, p<.001, \eta_{p}{ }^{2}=.28$. Further pairwise comparisons with Bonferroni correction showed that the facilitatory effect of voluntary choice under the confirmed causal relation (Experiment 1A) and the unrevealed relation (Experiment 1B) were larger than the effect under the defeated causal relation (Experiment $1 \mathrm{C}$ ), all $p \mathrm{~s}<.001$, whereas there was no difference between the former two experiments, $p>.999$. Thus, Experiment 1 suggested that a voluntary choice may improve performance as long as the choice-outcome causation is "undefeated".

\subsection{Experiment 2}

In Experiment 2 where we aimed to replicate Experiment 1 with a within-subject design, the 2 (Choice Type: voluntary vs. forced) $\times 3$ (Choice-outcome Relation: confirmed, unrevealed vs. defeated) repeated-measures ANOVA showed a main effect of Choice Type, $F$ $(1,26)=7.20, p=.013, \eta_{p}{ }^{2}=.22$, with RTs of visual search being generally faster for the voluntary choice condition than for the forced choice condition; the main effect of Choiceoutcome Relation was not significant, $F(2,52)=0.89, p=.419, \eta_{p}{ }^{2}=.03$. Importantly, there was a significant interaction effect (Figure 3A), $F(2,52)=3.52, p=.037, \eta_{p}^{2}=.12$. Planned $t$ test on simple effects showed that participants responded faster after a voluntary choice than after a forced choice under the confirmed causal relation, $t(26)=2.13, p=.043, d=0.41$, and the unrevealed relation, $t(26)=3.31, p=.003, d=0.64$, but not under the defeated causal 
relation, $t(26)=0.26, p=.795, d=0.05$. The later null effect was also confirmed by the $\mathrm{BF}_{01}$ $=4.75$. Thus, the pattern of effects in Experiment 1 with a between-subject design (Figure 2D) was replicated in Experiment 2 with a within-subject design (Figure 3A), even though overall the sizes of effect were reduced in the latter (see Table 1).
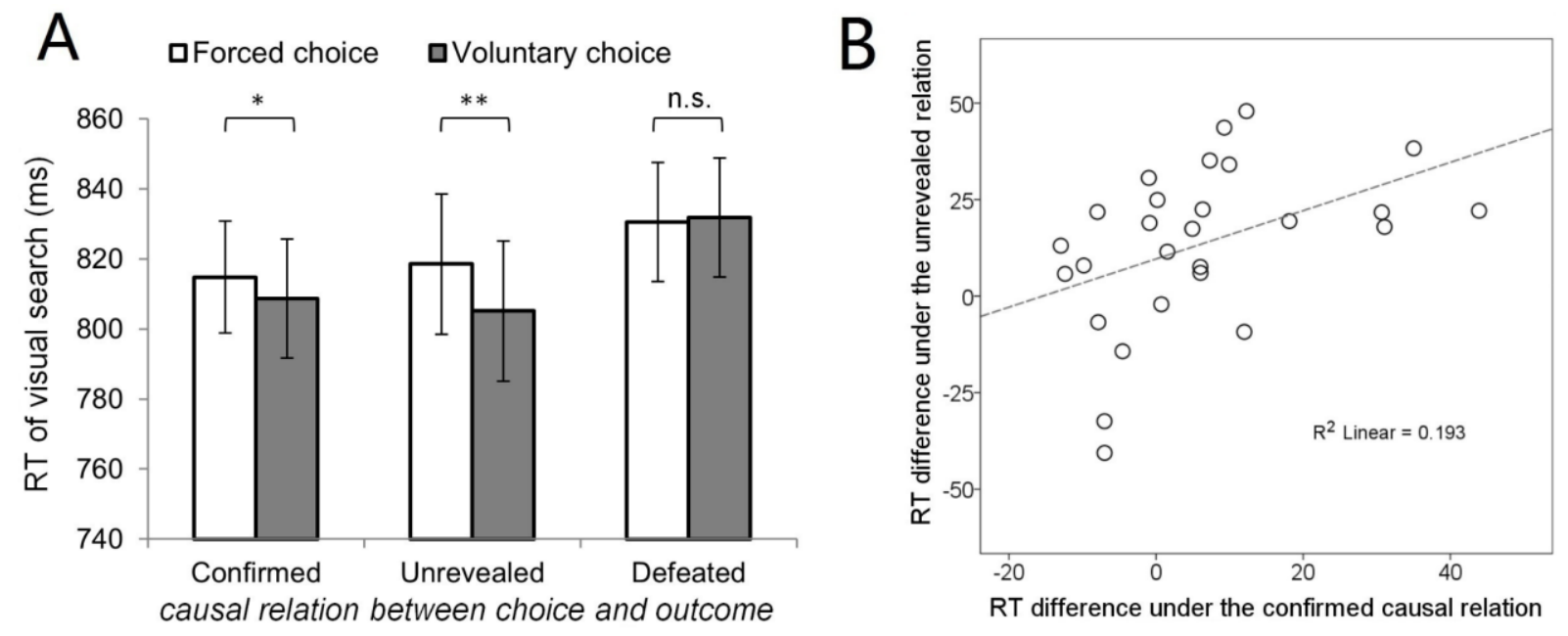

Figure 3 Results of Experiment 2. (A) The reaction time (RT) of visual search as a function of Choice Type and Choice-outcome Relation. (B) The RT difference between the voluntary and forced choice conditions under the confirmed causal relation positively correlated with the RT difference under the unrevealed relation. ${ }^{*} p<.05,{ }^{*} p<.01$, n.s., $p>.05$, error bars denote SEM.

A further analysis was conducted to examine to what extent the facilitatory effect of voluntary choice under the confirmed causal relation correlated, over individuals, with the effect under the unrevealed relation (Figure 3B). The $r=.44, p=.022$, suggesting that the facilitatory effect of voluntary choice under these two different choice-outcome relations might share common processes, which afford a belief in controlling the outcome by making voluntary choices.

In addition, to exclude the possible influence from the difference of chosen picture between conditions, we also conducted similar control analyses similar to those in Experiment 1 for Experiments 2 - 5 (see Additional Control Analyses in Supplementary Materials). 


\subsection{Experiment 3}

In Experiment 3 where the background picture was a constant picture different from the options (i.e., a predictable but uncontrollable outcome, the choice-outcome causation was again defeated, Figure 1D), participants showed comparable search RTs between the voluntary and forced choice conditions (Table 1$), t(22)=1.26, p=.223, d=0.26, \mathrm{BF}_{01}=$ 2.28, ruling out the predictability account (see also Buehner \& Humphreys, 2009).

\subsection{Experiment 4}

In Experiment 4 where a no choice condition was added to serve as a baseline condition (the bottom-left panel of Figure 1), the repeated-measures ANOVA (Choice Type: voluntary choice, forced choice, vs. no choice) showed a significant main effect, $F(2,46)=6.47, p$ $=.003, \eta_{p}^{2}=.22$. Further pairwise comparisons with Bonferroni correction showed that participants responded faster in the voluntary choice condition than in the forced choice condition (Table 1), $p=.025$, and the no choice condition, $p=.005$, whereas the search RTs did not differ between the forced and no choice conditions, $p>.999$. Therefore, the observed facilitatory effects of voluntary choice cannot be explained by demotivated performance after a forced choice but by motivated performance after a voluntary choice.

\subsection{Experiment 5}

In Experiment 5 where the background picture was always the unchosen picture (i.e., the actual choice was unfulfilled, but the choice-outcome causation was still confirmed, Figure 1E), we again found that participants responded faster in the search task after a voluntary choice than after a forced choice (Table 1$), t(35)=2.49, p=.018, d=0.42$.

For the analysis of post-experiment reports (Figure 4A), in the voluntary (vs. forced) choice condition, participants reported stronger belief in controlling the outcome of choice 
(5.1 vs. 2.6$), t(35)=9.41, p<.001, d=1.56$, as well as higher happiness ( 4.8 vs. 3.9$), t(35)$ $=3.33, p=.002, d=0.56$, and preference (4.8 vs. 4.1$), t(35)=2.68, p=.011, d=0.45$, for the visual search task, although they did not report a difference in the task difficulty between conditions (3.1 vs. 2.9), $t(35)=0.83, p=.414, d=0.12, \mathrm{BF}_{01}=4.07$.
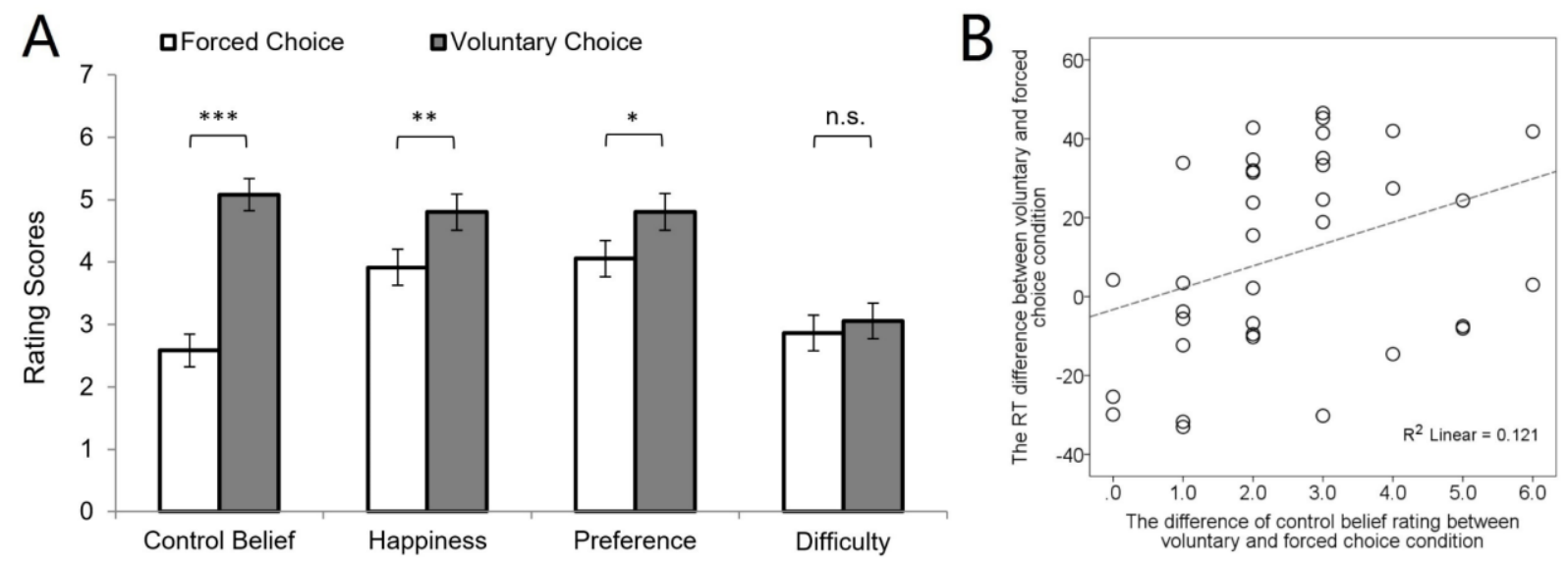

Figure 4 Results of Experiment 5. (A) Different subjective rating scores (on the x-axis, including the belief in controlling the outcome of the choice, the happiness during the task, the preference for the task, and the task difficulty) as a function of Choice Type. (B) The RT difference between the voluntary and forced choice conditions positively correlated with the rating difference of control belief between the two conditions. ${ }^{*} p<.05$, ${ }^{*} p<.01$, ${ }^{* * *} p$ $<.001$, n.s., $p>.05$, error bars denote SEM.

Moreover, the RT difference between the voluntary and forced choice conditions positively correlated with the rating difference in the control belief (Figure 4B), $r_{l}=.348, p$ $=.038$, but not with the rating difference in happiness, $r_{2}=-.070, p=.687$, or preference, $r_{3}$ $=.010, p=.952$. Direct comparison between the correlation coefficients (Diedenhofen $\&$ Musch, 2015, http://comparingcorrelations.org/) according to Meng et al.’s $z$ (Meng, Rosenthal, \& Rubin, 1992) showed that $r_{l}$ was significantly larger than $r_{2}, z=2.25, p=.025$, and was marginally larger than $r_{3}, z=1.71, p=.087$. Taken together, these results demonstrated again the importance of the undefeated choice-outcome causation which affords a belief in controlling the outcome of choice in enhancing behavioral performance. 


\subsection{RTs in each block}

To explore the dynamic change of the facilitatory effect by voluntary choice during experiments, we compared RTs between the voluntary and forced choice conditions in each experimental block. To ensure statistical power, we collapsed data from Experiments 1A, 1B, 2, and $5(n=111)$ in which a voluntary choice facilitated the performance. Note that RTs of Experiment 2 across the condition of confirmed causal relation and the condition of unrevealed relation were averaged. Experiment 4 was not included because there were 8 blocks in total and a no choice condition was mixed with the other two conditions.

Results showed that the facilitatory effect of voluntary choice increased over experimental blocks, evidenced by the marginally significant interaction between the Choice Type (voluntary vs. forced) and the Experimental Block $(1,2,3,4$, vs. 5), $F(4,440)=2.18, p$ $=.070, \eta_{p}^{2}=.02$ (Figure 5A), and the significant linear increasing trend of the RT difference between the conditions over blocks, $F(1,110)=4.40, p=.038, \eta_{p}^{2}=.04$ (Figure 5B).
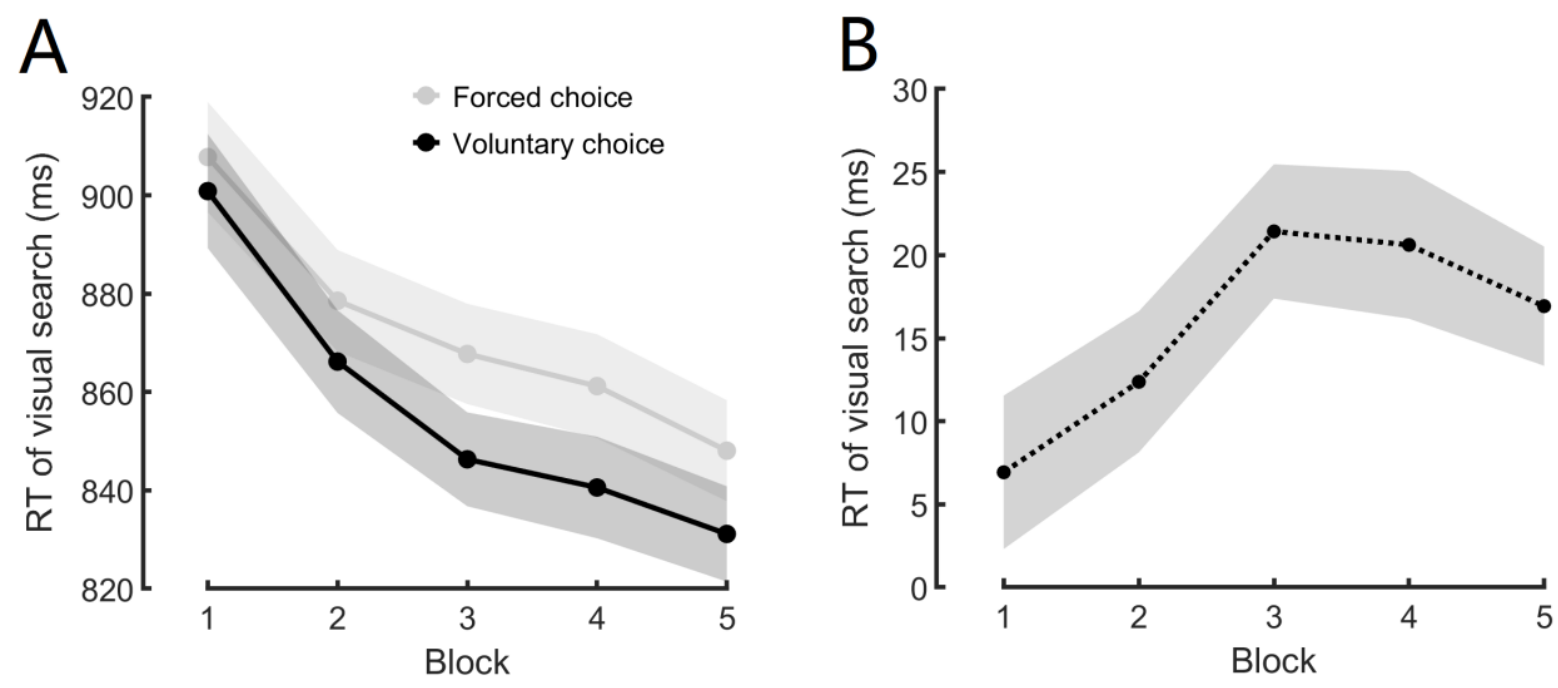

Figure 5 Dynamic change of the facilitatory effect of voluntary choice. Data were collapsed over Experiment 1A, 1B, 2, and 5. (A) The reaction times (RTs) of visual search as a function of Choice Type (voluntary, forced) and Experimental Block (1, 2, 3, 4, 5). (B) The RT difference between the voluntary and forced choice conditions as a function of Experimental Block. Shadows denote SEM. 


\subsection{EZ-diffusion model}

To explore the possible mechanism underlying the facilitatory effect of voluntary choice, we applied the EZ-diffusion model (Wagenmakers, van der Maas, \& Grasman, 2007), which is a variant of the drift diffusion model (Ratcliff, 1978; Ratcliff \& McKoon, 2008), to obtain the speed of information accumulation (i.e., drift rate, $v$ ), response criterion (i.e., boundary separation, $a$ ), and the time spent on processes that are not directly involved in discriminating between response alternatives, such as motor execution (i.e., nondecision time, $T_{e r}$ ), during visual search. The advantage of using the EZ-diffusion model is that it can be applied to datasparse situations but still holds power to detect experimental effects (van Ravenzwaaij, Donkin, \& Vandekerckhove, 2017; Wagenmakers et al., 2007).

Specifically, for each participant, the mean reaction time of correct responses (i.e., $M R T$ ), the variance of correct responses (i.e., $V R T$ ), and the proportion of correct responses (i.e., $P_{c}$ ) in the visual search task were calculated as the input for the EZ-diffusion model. As the output, the model generates values of $v, a$, and $T_{e r}$ without the complicated parameterfitting exercise (Wagenmakers et al., 2007, the codes of the current study can be accessed at https://osf.io/jx93g/). The parameters were respectively obtained for the voluntary and forced choice conditions.

Again, to ensure statistical power, we collapsed data from Experiments 1A, 1B, (part of) 2, and 5 (i.e., the confirmed/unrevealed choice-outcome relation, $n=111$ ) where the facilitatory effect by the voluntary choice was observed (as described above), and collapsed data from Experiment 1C, (part of) 2, and 3 (i.e., the defeated choice-outcome causation, $n=$ 74) where the facilitatory effect was not observed. 

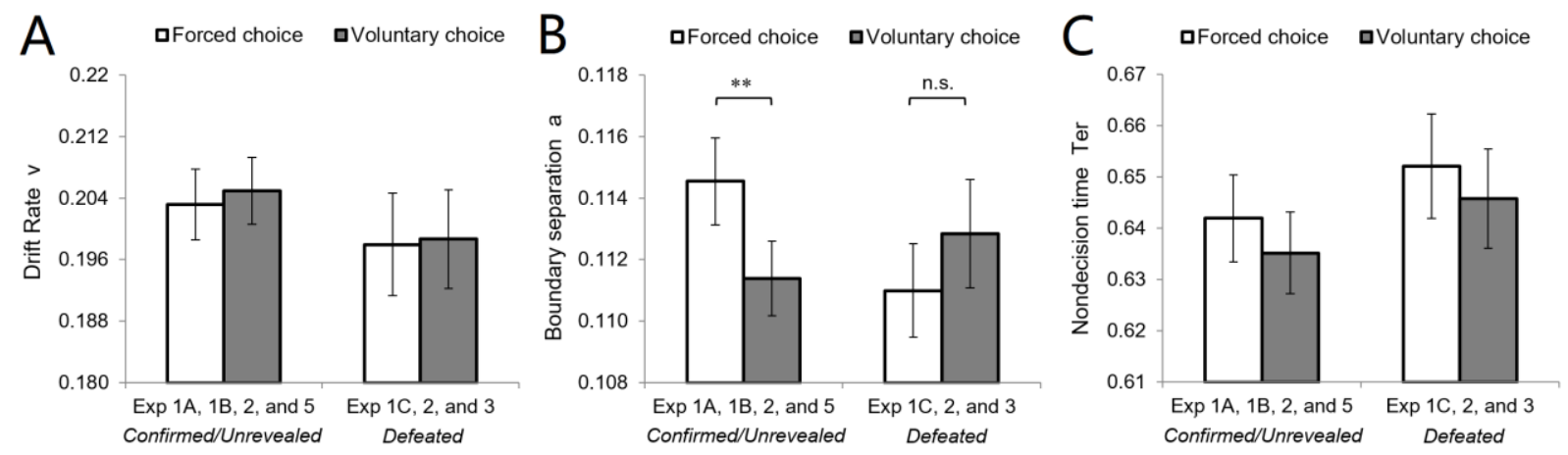

Figure 6 Parameters of the EZ-diffusion model are shown as a function of Choice Type and Experiment Group. (A) Drift rate $v$. (B) boundary separation $a$. (C) Nondecision time $T_{e r} * * p$ $<.01$, n.s., $p>.05$, error bars denote SEM.

For the drift rate $v$ (Figure 6A), the 2 (Choice Type: voluntary vs. forced) $\times 2$ (Experiment Group: confirmed/unrevealed relation vs. defeated relation) mixed-measures ANOVA showed no significant main effect or interaction, all $F \mathrm{~s}(1,183)<1, p \mathrm{~s}>.436$.

For the boundary separation $a$ (Figure $6 \mathrm{~B}$ ), the $2 \times 2$ mixed-measures ANOVA showed no significant main effect, all $F_{\mathrm{s}}(1,183)<1, p \mathrm{~s}>.449$, but a significant interaction between Choice Type and Experiment Group, $F(1,183)=8.37, p=.004, \eta_{p}{ }^{2}=.04$. Planned $t$ test on simple effects showed that in the experiments with confirmed/unrevealed relation, the $a$ was significantly lower in the voluntary choice condition than in the forced choice condition $(0.1114$ vs. 0.1145$), t(110)=2.77, p=.007, d=0.26$; Whereas in experiments with defeated relation, the difference was not significant (0.1128 vs. 0.1110$), t(73)=1.47, p=.145, d=$ $0.17, \mathrm{BF}_{01}=2.72$.

For the nondecision time $T_{e r}$ (Figure 6C), the $2 \times 2$ mixed-measures ANOVA showed only a significant main effect of Choice Type, $F(1,183)=12.88, p<.001, \eta_{p}{ }^{2}=.07$, indicating that the $T_{e r}$ was generally shorter in the voluntary choice condition than in the forced choice condition ( 0.6394 s vs. 0.6460 s). The main effect of Experiment Group and the interaction were not significant, all $F \mathrm{~s}(1,183)<1, p \mathrm{~s}>.420$. 


\section{Discussion}

In a series of experiments, we demonstrated that relative to a forced choice, making a voluntary choice between two pictures improved the subsequent visual search performance (shorter RT). This effect, however, was present only when the choice-outcome causation was confirmed (Experiments 1A, 2, 4, and 5), or at least not undermined (i.e., unrevealed choiceoutcome relation, Experiments 1B and 2), but was absent when the choice-outcome causation was defeated (Experiments 1C, 2 and 3). These findings demonstrated that making a (taskirrelevant) voluntary choice motivates the subsequent behaviour, and this effect is restricted to an undefeated choice-outcome causation.

Moreover, individuals who showed larger improvement through voluntary choice under the confirmed causal relation also showed larger improvement under the unrevealed relation (Experiment 2); they also reported higher belief in controlling the background picture of visual search (Experiment 5). These results suggested that the facilitatory effect of voluntary choice on different situations may be related to a common process - the belief in controlling the outcome of the voluntary choice, which is afforded by the undefeated choice-outcome causation. The fact that the magnitude of improvement through voluntary choice increased as a function of visual search blocks could be construed as a consequence of the build-up over time of the belief in controlling the choice outcome.

Furthermore, we tested alternative accounts in explaining the facilitatory effect. First, we excluded the predictability of the outcome as explanation by showing that the facilitatory effect was absent when the outcome of choice is predictable but uncontrollable by the choice (i.e., a defeated choice-outcome causation, Experiment 3). Second, we demonstrated that the performance difference was due to improved performance through voluntary choice, but not impaired performance through forced choice (Experiment 4).

At last, relying on the EZ-diffusion model, we examined the mechanism underlying the facilitatory effect. The response criterion in the visual search task was more liberal (lower 
boundary separation $a$ ) after a voluntary choice than after a forced choice when the choiceoutcome causation was undefeated, but this effect was absent when the choice-outcome causation was defeated. On the other hand, the execution of response in the visual search task was generally faster (shorter nondecision time $T_{e r}$ ) after a voluntary choice than a forced choice, regardless of the choice-outcome relation.

\subsection{The facilitatory effect of voluntary choice and the belief in control}

The facilitatory effect of a task-irrelevant voluntary choice on the subsequent task performance may reflect an improvement in motivation caused by making a voluntary choice (i.e., a pure expression of volition) regardless of the options. This is in line with the view that voluntarily making choices is a basic psychological need (Deci \& Ryan, 1985; Leotti et al., 2010). It has been shown that providing opportunities to make voluntary choices improves intrinsic motivation (Patall et al., 2008), and the anticipation of a voluntary choice activates reward-related brain areas (e.g., striatum) (Leotti \& Delgado, 2011, 2014; Murayama et al., 2015; Murty et al., 2015). Making a voluntary choice may be an inherent reward in the human brain (Leotti \& Delgado, 2011), facilitating behavioral performance within a certain temporal window, which may be a performance-enhancing effect of phasic dopamine associated with instrumental actions (Redgrave, Prescott, \& Gurney, 1999).

Importantly, this motivated performance through voluntary choice was restricted to "undefeated" choice-outcome causation scenarios, that is, the performance-enhancing benefit is confined to conditions where the voluntary choice is believed to make a difference to the unfolding of subsequent events, demonstrating the importance of the belief in controlling the environment by making a voluntary choice. This belief may be strengthened due to repeated confirmation of the choice-outcome causation, leading to increased magnitude of the improvement by voluntary choice over time. Our findings are reminiscent of studies on the sense of agency which refers to the experience of controlling one's own action and the course 
of events in the outside world (Haggard, 2017, 2019). It has been shown that the sense of agency is stronger when the action is voluntary than when it is forced (Barlas, Hockley, \& Obhi, 2018; Caspar, Christensen, Cleeremans, \& Haggard, 2016). Crucially, the strength of the sense of agency depends on to what extent the outcome is believed to be caused by the action (Desantis et al., 2011; Dogge et al., 2012). Our findings are also consistent with the control-based response selection framework which proposes that control-relevant information modulates individuals' motivation by determining whether a perceptual event is an outcome of one's actions or not (Eitam et al., 2013; Karsh et al., 2016; Karsh \& Eitam, 2015). Moreover, the feeling of determining the outcome by taking voluntary actions may be interpreted as the experience of "free will" (Baumeister, 2008), and inducing disbelief in free will attenuates motor responses to a voluntary action (Rigoni et al., 2011) and reduces the behavioral adjustment after performance error (Rigoni, Wilquin, Brass, \& Burle, 2013). The converging evidence suggests that the belief in control serves as a building block of human volition (Wegner \& Wheatley, 1999).

\subsection{Unrevealed and defeated choice-outcome relations and the belief in control}

On the surface, a voluntary choice that is not followed by an immediate outcome (e.g., the "no background picture" situation in Experiment 1B, which we termed as an "unrevealed choice-outcome relation") is quite similar to a voluntary choice that is followed by a predictable, but uncontrollable outcome (e.g., a constant picture that was different from preceding optional pictures in Experiment 3, which we termed as a "defeated choice-outcome causation"). However, the subsequent task performance is facilitated by the voluntary choice in the former situation, not in the latter. The key difference between these two situations is that whether an immediate outcome related to the preceding choice is explicitly provided (i.e., whether a picture is displayed after choosing between pictures). 
The facilitated performance by voluntary choices under the unrevealed relation might occur as a result of the illusion of control which refers to the fact that individuals tend to believe that their voluntary actions always have an intended influence on the outcome, despite the uncontrollable nature of the situation (Langer, 1975; Thompson, Armstrong, \& Thomas, 1998). Similarly, individuals could still experience the sense of agency even when a voluntary action was not followed by an effect (Moore et al., 2009; Moore \& Haggard, 2008). The improved performance by a voluntary choice in the absence of outcome was also observed in another study where the cost of switching between different trials (relative to repeated trials) was lower when the target of visual search could be freely chosen from two alternatives than when the search target was imposed (Ort, Fahrenfort, \& Olivers, 2017). It is possible that the belief in control can be (implicitly) present even when the outcome of choice is not seen, reflecting a default assumption that one's choice make a difference to external events, i.e., agency, which is the normal experience of healthy adults (Haggard, 2017). In real life, people often make a choice while expecting the potential outcome in a "deterministic" way - they tend to believe that there is a causal relation between their choice and the desired outcome. When individuals have made a choice, they will explicitly or implicitly "seek" the outcome of that choice and behave in a motivated way as if they can control the unseen outcome, which might be an important evolutionary surviving strategy for humans in a world full of uncertainties.

The explicitly shown outcome (e.g., a background picture), which is closely related to the preceding choice (e.g., choosing a picture), may lead individuals to build a causal relation between the choice and that outcome (Desantis et al., 2011; Dogge et al., 2012; Moore \& Haggard, 2008). If this outcome, however, is always different from preceding options (Experiment 3), or randomly presented (Experiment 1C), the assumed casual relation between the choice and the outcome would be defeated, leading to a disbelief in controlling the outcome of the choice and the absence of enhanced performance through voluntary choice. 
This was concurred with models on maladaptive behaviors such as learned helplessness and depression (Huys \& Dayan, 2009; Mineka \& Hendersen, 1985). Individuals with a history of exposure to uncontrollable aversive events display feelings of helplessness and a lack of motivation to take actions in a new environment (Mineka \& Hendersen, 1985). Similarly, negative emotional states (e.g., fear and anger) associated with loss of control would decrease the sense of agency (Christensen, Di Costa, Beck, \& Haggard, 2019). Computational modelling suggests that the action-outcome contingencies are derived to predict to what extent the environment can be controlled, and depressive behaviors result from a mismatch between the derived prediction and the new environment's contingencies (Huys \& Dayan, 2009). On this ground, a voluntary choice that cannot control the outcome may lead to a "transient learned helplessness or depression" that makes individuals feel loss of control. In other words, making voluntary choices to achieve yearning outcomes enables the feeling of control and healthy functioning.

\subsection{Two possible routes to the facilitatory effect of voluntary choice}

According to the EZ-diffusion modelling, the facilitatory effect of voluntary choice may arise out of two possible routes - the facilitation of the belief in control, and the facilitation of the act of making a voluntary choice itself. On the one hand, making a voluntary choice that is believed to control the (unrevealed) outcome may lead to a more liberal response criterion (lower boundary separation $a$ ) in the subsequent task compared to a forced choice; however, making a voluntary choice that could not control the outcome did not change the response criterion. These results are reminiscent of findings that a voluntary choice may act as an inherent reward (Leotti \& Delgado, 2011, 2014; Murayama et al., 2015; Murty et al., 2015) and reward-related incentives may lead to a more liberal response criterion than non-reward incentives (Bowen, Marchesi, \& Kensinger, 2020; Luo, Kang, Guo, Yu, \& Zhou, 2020). Depressive individuals did not show this reward-related change of response criterion 
(Henriques \& Glowacki, 1994) but showed a less liberal response criterion compared to nondepressive individuals (Lawlor, Webb, Wiecki, Frank, Trivedi, \& Pizzagalli et al., 2020), supporting our suggestion that a "transient learned helplessness or depression" occurred when the outcome could not be controlled by a voluntary choice. It is possible that the undefeated choice-outcome causation ensures the belief in controlling the outside environment and renders voluntary choice equivalent to "reward" (i.e., gaining control) (see also Eitam et al., 2013; Karsh et al., 2016). This reward-like motivation is carried over into the subsequent cognitive task, biasing the response criterion.

On the other hand, an act of making a voluntary choice may generally facilitate the subsequent action execution regardless of the outcome, as indicated by the generally shorter nondecision time after a voluntary choice than a forced choice. This general facilitation in action execution is often overlooked in previous studies, which may be related with the stronger activation of the motor system in the brain (e.g., the supplementary motor area) by the self-generated action (e.g., a voluntary choice) compared with the stimulus-guided action (e.g., a forced choice) (Cunnington, Windischberger, Deecke, \& Moser, 2002; Deiber, Honda, Ibañez, Sadato, \& Hallett, 1999). As a result, the activation of the motor system after making a voluntary choice is carried over into the subsequent cognitive task, facilitating the processing of response execution.

\subsection{Implications of the current study}

Using the visual search task as an example, the current study closely investigated the conditions where performance is influenced by (even task-irrelevant) voluntary choices. In real world scenarios, making a voluntary choice is an easy way to gain control and improve performance in the subsequent task, such as having students voluntarily choose their homework in order to facilitate academic performance (Patall et al., 2010), and having motor learners freely choose the practice context to benefit motor learning (Sanli et al., 2013). This 
facilitatory effect of voluntary choice becomes especially valuable and promising since even making a task-irrelevant voluntary choice matters (e.g., the present study, see also Lewthwaite et al., 2015; Murayama et al., 2015). Individuals' performance may be improved even when they are nudged through a subtle, irrelevant voluntary choice. The current findings further suggest that the facilitation is conditional - the belief in controlling the outcome of the choice has to be (either explicitly or implicitly) held, and an uncontrollable outcome after the choice should be avoided.

Apart from the broad implications for designing task structures to motivate people and enhance task performance in real life, our findings may be inspiring for a reconciliation of the philosophical debate concerning free will and causal determinism - free will only matters in causally deterministic scenarios. Humans need free will (e.g., to make a voluntary choice based on their own will) to ensure the well-functioning of motivation and mental health, and humans also need at least local causal determinism (e.g., a causal relation between their choice and the outcome of their choice) to ensure successful functioning of the psychological apparatus of volition itself. It is possible that belief in free will reflects a functionally successful, and therefore positively-selected, performance enhancing byproduct of endogenous choice.

\subsection{Conclusion}

The present study revealed that making a (task-irrelevant) voluntary choice facilitates the subsequent behavioral performance. This facilitation is restricted to an undefeated choiceoutcome causation which affords a belief in controlling the outcome of the choice. Our findings demonstrate the scope of the impact of human volition, and suggest that only providing the opportunity of free choice or just making an act of free choice is insufficient to motivate subsequent behavior. Humans not only need to exercise volition to get motivated and ensure mental health, but also need their volition to have causally determining effects on 
the outcome events to ensure successful functioning of the psychological apparatus of volition itself. 


\section{Acknowledgments}

We thank Prof. Patrick Haggard and Dr. Yiwen Zhan for their constructive comments and suggestions. We also thank Ms. Ziyun Wu for help in collecting the data of Experiment $1 \mathrm{~B}$.

This study was supported by the National Natural Science Foundation of China (31861133012) and by the China Postdoctoral Science Foundation (2020M681216). Lihui Wang is supported by the Shanghai Sailing Program (20YF1422100).

\section{Author Contributions}

All authors developed the study concept and contributed to the study design. Testing and data collection were performed by X. Luo. X. Luo and L. Wang performed the data analysis and interpretation under the supervision of X. Zhou. L. Wang and X. Luo drafted the manuscript, and X. Zhou provided critical revisions. All authors approved the final version of the manuscript for submission.

\section{Declaration of Competing Interest}

None.

\section{Data availability}

All data, codes, and materials can be accessed at https://osf.io/jx93g/ 


\section{References}

Bandura, A., \& Wood, R. (1989). Effect of perceived controllability and performance standards on selfregulation of complex decision making. Journal of Personality and Social Psychology, 56(5), 805814. http://doi.org/10.1037//0022-3514.56.5.805

Barlas, Z., Hockley, W. E., \& Obhi, S. S. (2018). Effects of free choice and outcome valence on the sense of agency: Evidence from measures of intentional binding and feelings of control. Experimental Brain Research, 236, 129-139. http://doi.org/10.1007/s00221-017-5112-3

Baumeister, R. F. (2008). Free will in scientific psychology. Perspectives on Psychological Science, 3(1), 14-19. http://doi.org/10.1111/j.1745-6916.2008.00057.x

Bowen, H. J., Marchesi, M. L., \& Kensinger, E. A. (2020). Reward motivation influences response bias on a recognition memory task. Cognition, 203, 104337. http://doi.org/10.1016/j.cognition.2020.104337

Brainard, D. H. (1997). The Psychophysics Toolbox. Spatial Vision, 10(4), 433-436. http://doi.org/10.1163/156856897x00357

Buehner, M. J., \& Humphreys, G. R. (2009). Causal binding of actions to their effects. Psychological Science, 20(10), 1221-1228. http://doi.org/10.2307/40575171

Caspar, E. A., Christensen, J. F., Cleeremans, A., \& Haggard, P. (2016). Coercion changes the sense of agency in the human brain. Current Biology, 26, 585-592. http://doi.org/10.1016/j.cub.2015.12.067

Chambon, V., Théro, H., Vidal, M., Vandendriessche, H., Haggard, P., \& Palminteri, S. (2020). Information about action outcomes differentially affects learning from self-determined versus imposed choices. Nature Human Behaviour, 4, 1067-1079. http://doi.org/10.1038/s41562-020-0919-5

Christensen, J. F., Di Costa, S., Beck, B., \& Haggard, P. (2019). I just lost it! Fear and anger reduce the sense of agency: A study using intentional binding. Experimental Brain Research, 237(5), 1205-1212. http://doi.org/10.1007/s00221-018-5461-6

Cunnington, R., Windischberger, C., Deecke, L., \& Moser, E. (2002). The preparation and execution of self-initiated and externally-triggered movement: A study of event-related fMRI. NeuroImage, 15(2), 373-385. http://doi.org/10.1006/nimg.2001.0976

Deci, E. L., \& Ryan, R. M. (1985). Intrinsic motivation and self-determination in human behavior. New York: Springer Science+Business Media

Deiber, M., Honda, M., Ibañez, V., Sadato, N., \& Hallett, M. (1999). Mesial motor areas in self-initiated 
versus externally triggered movements examined with fMRI: Effect of movement type and rate. Journal of Neurophysiology, 81(6), 3065-3077. http://doi.org/10.1152/jn.1999.81.6.3065

Desantis, A., Roussel, C., \& Waszak, F. (2011). On the influence of causal beliefs on the feeling of agency. Consciousness and Cognition, 20, 1211-1220. http://doi.org/10.1016/j.concog.2011.02.012

Diedenhofen, B., \& Musch, J. (2015). cocor: A comprehensive solution for the statistical comparison of correlations. PLoS ONE, 10(4), e121945. http://doi.org/10.1371/journal.pone.0121945

Dogge, M., Schaap, M., Custers, R., Wegner, D. M., \& Aarts, H. (2012). When moving without volition: Implied self-causation enhances binding strength between involuntary actions and effects. Consciousness and Cognition, 21(1), 501-506. http://doi.org/10.1016/j.concog.2011.10.014

Eitam, B., Kennedy, P. M., \& Higgins, E. T. (2013). Motivation from control. Experimental Brain Research, 229(3), 475-484. http://doi.org/10.1007/s00221-012-3370-7

Elsner, B., \& Hommel, B. (2004). Contiguity and contingency in action-effect learning. Psychological Research, 68, 138-154. http://doi.org/10.1007/s00426-003-0151-8

Faul, F., Erdfelder, E., Lang, A., \& Buchner, A. (2007). G*Power 3: A flexible statistical power analysis program for the social, behavioral, and biomedical sciences. Behavior Research Methods, 39, 175-191. http://doi.org/10.3758/BF03193146

Haggard, P. (2017). Sense of agency in the human brain. Nature Reviews Neuroscience, 18(4), 196-207. http://doi.org/10.1038/nrn.2017.14

Haggard, P. (2019). The neurocognitive bases of human volition. Annual Review of Psychology, 70, 9-28. http://doi.org/10.1146/annurev-psych-010418-103348

Henriques, J. B., \& Glowacki, J. M. (1994). Reward fails to alter response bias in depression. Journal of Abnormal Psychology, 103(3), 460-466. http://doi.org/10.1037/0021-843X.103.3.460

Huys, Q. J. M., \& Dayan, P. (2009). A Bayesian formulation of behavioral control. Cognition, 113(3), 314328. http://doi.org/10.1016/j.cognition.2009.01.008

Karsh, N., Eitam, B., Mark, I., \& Higgins, E. T. (2016). Bootstrapping agency: How control-relevant information affects motivation. Journal of Experimental Psychology: General, 145(4), 1333-1350. http://doi.org/10.1037/xge0000212

Karsh, N., \& Eitam, B. (2015). I control therefore I do: Judgments of agency influence action selection. Cognition, 138, 122-131. http://doi.org/10.1016/j.cognition.2015.02.002

Langer, E. J. (1975). The illusion of control. Journal of Personality \& Social Psychology, 32(2), 311-328. 
http://doi.org/10.1037/0022-3514.32.2.311

Lawlor, V. M., Webb, C. A., Wiecki, T. V., Frank, M. J., Trivedi, M., \& Pizzagalli, D. A. et al. (2020). Dissecting the impact of depression on decision-making. Psychological Medicine, 50(10), 1613-1622. http://doi.org/10.1017/S0033291719001570

Leotti, L. A., Iyengar, S. S., \& Ochsner, K. N. (2010). Born to choose: The origins and value of the need for control. Trends in Cognitive Sciences, 14(10), 457-463. http://doi.org/10.1016/j.tics.2010.08.001

Leotti, L. A., \& Delgado, M. R. (2011). The inherent reward of choice. Psychological Science, 22(10), 1310-1318. http://doi.org/10.1177/0956797611417005

Leotti, L. A., \& Delgado, M. R. (2014). The value of exercising control over monetary gains and losses. Psychological Science, 25(2), 596-604. http://doi.org/10.1177/0956797613514589

Lewthwaite, R., Chiviacowsky, S., Drews, R., \& Wulf, G. (2015). Choose to move: The motivational impact of autonomy support on motor learning. Psychonomic Bulletin \& Review, 22, 1383-1388. http://doi.org/10.3758/s13423-015-0814-7

Luo, X., Kang, G., Guo, Y., Yu, X., \& Zhou, X. (2020). A value-driven McGurk effect: Value-associated faces enhance the influence of visual information on audiovisual speech perception and its eye movement pattern. Attention, Perception, \& Psychophysics, 82, 1928-1941. http://doi.org/10.3758/s13414-019-01918-x

Meng, X., Rosenthal, R., \& Rubin, D. B. (1992). Comparing correlated correlation coefficients. Psychological Bulletin, 111(1), 172-175. http://doi.org/10.1037/0033-2909.111.1.172

Mineka, S., \& Hendersen, R. W. (1985). Controllability and predictability in acquired motivation. Annual Review of Psychology, 36, 495-529. http://doi.org/10.1146/annurev.ps.36.020185.002431

Moore, J. W., Lagnado, D., Deal, D. C., \& Haggard, P. (2009). Feelings of control: Contingency determines experience of action. Cognition, 110(2), 279-283. http://doi.org/10.1016/j.cognition.2008.11.006

Moore, J., \& Haggard, P. (2008). Awareness of action: Inference and prediction. Consciousness and Cognition, 17(1), 136-144. http://doi.org/10.1016/j.concog.2006.12.004

Murayama, K., Izuma, K., Aoki, R., \& Matsumoto, K. (2016). "Your choice" motivates you in the brain: The emergence of autonomy neuroscience. Recent Developments in Neuroscience Research on Human Motivation, 19, 9-25. http://doi.org/10.1108/S0749-742320160000019004

Murayama, K., Matsumoto, M., Izuma, K., Sugiura, A., Ryan, R. M., \& Deci, E. L. et al. (2015). How self- 
determined choice facilitates performance: A key role of the ventromedial prefrontal cortex. Cerebral Cortex, 25(5), 1241-1251. http://doi.org/10.1093/cercor/bht317

Murty, V. P., DuBrow, S., \& Davachi, L. (2015). The simple act of choosing influences declarative memory. Journal of Neuroscience, 35(16), 6255-6264. http://doi.org/10.1523/JNEUROSCI.418114.2015.

Ort, E., Fahrenfort, J. J., \& Olivers, C. N. L. (2017). Lack of free choice reveals the cost of having to search for more than one object. Psychological Science, 28(8), 1137-1147. http://doi.org/10.1177/0956797617705667

Patall, E. A. (2019). The complex role of choice in human motivation and functioning. In R. M. Ryan (Ed.), The Oxford Handbook of Human Motivation, 2nd edition (135-155). New York: NY: Oxford University Press. (Reprinted.

Patall, E. A., Cooper, H., \& Robinson, J. C. (2008). The effects of choice on intrinsic motivation and related outcomes: A meta-analysis of research findings. Psychological Bulletin, 134(2), 270-300. http://doi.org/10.1037/0033-2909.134.2.270

Patall, E. A., Cooper, H., \& Wynn, S. R. (2010). The effectiveness and relative importance of choice in the classroom. Journal of Educational Psychology, 102(4), 896-915. http://doi.org/10.1037/a0019545

Ratcliff, R. (1978). A theory of memory retrieval. Psychological Review, 85(2), 59-108. http://doi.org/10.1037/0033-295X.85.2.59

Ratcliff, R., \& McKoon, G. (2008). The diffusion decision model: Theory and data for two-choice decision tasks. Neural Computation, 20, 873-922. http://doi.org/10.1162/neco.2008.12-06-420

Reber, R., Canning, E. A., \& Harackiewicz, J. M. (2018). Personalized education to increase interest. Current Directions in Psychological Science, 27(6), 449-454. http://doi.org/10.1177/0963721418793140

Redgrave, P., Prescott, T. J., \& Gurney, K. (1999). Is the short-latency dopamine response too short to signal reward error? Trends in Neurosciences, 22(4), 146-151. http://doi.org/10.1016/S01662236(98)01373-3

Rigoni, D., Kühn, S., Sartori, G., \& Brass, M. (2011). Inducing disbelief in free will alters brain correlates of preconscious motor preparation: The brain minds whether we believe in free will or not. Psychological Science, 22(5), 613-618. http://doi.org/10.1177/0956797611405680

Rigoni, D., Wilquin, H., Brass, M., \& Burle, B. (2013). When errors do not matter: Weakening belief in 
intentional control impairs cognitive reaction to errors. Cognition, 127(2), 264-269.

http://doi.org/10.1016/j.cognition.2013.01.009

Sanli, E. A., Patterson, J. T., Bray, S. R., \& Lee, T. D. (2013). Understanding self-controlled motor learning protocols through the self-determination theory. Frontiers in Psychology, 3, 611. http://doi.org/10.3389/fpsyg.2012.00611

Soon, C. S., Brass, M., Heinze, H., \& Haynes, J. (2008). Unconscious determinants of free decisions in the human brain. Nature Neuroscience, 11, 543-545. http://doi.org/10.1038/nn.2112

Theeuwes, J. (1991). Cross-dimensional perceptual selectivity. Perception \& Psychophysics, 50(2), 184193. http://doi.org/10.3758/bf03212219

Thompson, S. C., Armstrong, W., \& Thomas, C. (1998). Illusions of control, underestimations, and accuracy: A control heuristic explanation. Psychological Bulletin, 123(2), 143-161. http://doi.org/10.1037/0033-2909.123.2.143

van Ravenzwaaij, D., Donkin, C., \& Vandekerckhove, J. (2017). The EZ diffusion model provides a powerful test of simple empirical effects. Psychonomic Bulletin \& Review, 24, 547-556. http://doi.org/10.3758/s13423-016-1081-y

Wagenmakers, E. J., van der Maas, H. L. J., \& Grasman, R. P. P. P. (2007). An EZ-diffusion model for response time and accuracy. Psychonomic Bulletin \& Review, 14(1), 3-22. http://doi.org/10.3758/BF03194023

Wagenmakers, E., Love, J., Marsman, M., Jamil, T., Ly, A., \& Verhagen, J. et al. (2018). Bayesian inference for psychology. Part II: Example applications with JASP. Psychonomic Bulletin \& Review, 25, 58-76. http://doi.org/10.3758/s13423-017-1323-7

Wagenmakers, E., Marsman, M., Jamil, T., Ly, A., Verhagen, J., \& Love, J. et al. (2018). Bayesian inference for psychology. Part I: Theoretical advantages and practical ramifications. Psychonomic Bulletin \& Review, 25, 35-57. http://doi.org/10.3758/s13423-017-1343-3

Wegner, D. M., \& Wheatley, T. (1999). Apparent mental causation. American Psychologist, 54(7), 480492. http://doi.org/10.1037/0003-066X.54.7.480

Wolfe, J. M. (1994). Guided Search 2.0 A revised model of visual search. Psychonomic Bulletin \& Review, l(2), 202-238. http://doi.org/10.3758/BF03200774 